\title{
Research on full cycle evaluation of power grid projects based on rough set-multilevel extension theory
}

\author{
Yuheng Sha ${ }^{1, *}$, Jun Yan², Yanlai Zhang ${ }^{2}$, Wenlong $\mathrm{Li}^{2}$, Wenqi $\mathrm{Li}^{2}$, Yannan $\mathrm{Guo}^{2}$, Yuqian Zhang ${ }^{2}$, and Jing Zhang ${ }^{2}$ \\ ${ }^{1}$ State Grid Corporation Development Planning Department, 100031 Beijing, China \\ ${ }^{2}$ Tianjin Tianda Qiushi Electric Power New Technology, Co., Ltd., 300384 Tianjin, China
}

\begin{abstract}
Project full-cycle evaluation is the process of evaluating the level of project implementation. The evaluation has a clear purpose orientation and involves the entire cycle of the project. This paper proposes a research method for the full-cycle evaluation of power grid projects based on rough set-multi-level extension theory. First, this article combines various aspects of the project to establish a project evaluation index system involving multiple interests such as the environment and society. Then, the index weight is determined based on the rough set theory, and the multi-level extension theory is used to evaluate the project in the whole cycle. This model provides new ideas for the accurate evaluation of various types of projects and lays a theoretical foundation for improving the level of project management.
\end{abstract}

\section{Introduction}

In the context of the reform of the power system, although the investment in a single equipment of the distribution network is low, but the quantity is large and the scale of assets is large, it is an important direction for the future operation of the grid company [1]. This requires more effective and reasonable construction management of distribution network engineering projects. However, in actual work, there is no unified evaluation index system and evaluation method for the whole process evaluation of distribution network projects ${ }^{[2]}$.

In recent years, power systems have begun to apply full cycle system theory. In developed countries, there are many researches on the theory of power industry full-cycle systems and they are basically in the mature stage. In the United States, the full cycle system theory was first applied to the management of nuclear power plants [3]. In other countries, the full-cycle system management method is applied to other power facilities and equipment, such as generators, transformers, power transmission and distribution systems. [4-5]. In China, the theory of full-cycle systems is gradually being valued in the power industry. The literature [6] applies the theory of full-cycle systems to the work of power grid companies' investment decision-making and control. From the main stages of fixed asset investment in power grid companies, the impact investment is proposed. The main influencing factors of performance and corresponding management and control strategies are proposed. Based on the reform of transmission and distribution prices, the literature [7] proposed the "three excellent" power grid precision investment strategy from the three aspects of optimizing planning ideas, optimizing investment decision-making, and optimizing investment management and control. Literature [8] uses fuzzy comprehensive evaluation and multi-level gray comprehensive evaluation based on the perspective of the whole life cycle to establish an evaluation index system and method for the process management of science and technology planning projects. However, in actual work, many places lack the corresponding evaluation of the whole process of the construction of distribution network projects. This directly leads to a problem that can not be solved once in the construction of distribution network, and the recurrence of this type of problem greatly Affected the efficiency of power grid engineering construction.

Therefore, this article will conduct a full-cycle evaluation of distribution network engineering projects to achieve the improvement of project construction efficiency and management level, and ultimately achieve the goals of reducing investment, safe construction, and shortening the construction period of the distribution network engineering project.

\section{Project full-cycle system evaluation index system}

\subsection{Principles and Steps of Index System Construction}

A complete index system is the basis for project evaluation. This section mainly introduces the construction principles and steps of the evaluation index system after the distribution network project, and lays the foundation for the construction of the subsequent index system.

\footnotetext{
* Corresponding author: Yuhengsha@126.com
} 
The construction of the index system follows the following principles: systematic, practical and operability, combination of quantitative and qualitative, independence, and hierarchical.

Steps to construct the index system: First, determine the target level, that is, to clarify the evaluation objectives; second, establish the criterion level and analyse the characteristic elements of the evaluation object; third, establish the index level, and extend the index level if necessary.

\subsection{Construction of the System Evaluation Index System for the Whole Project Cycle}

Considering that the full-cycle system evaluation of a project is a multi-category and multi-level evaluation problem, it has to do with multiple dimensions such as power grids, equipment, etc., time, unit, etc., project investment benefits, project (equipment) efficiency, etc. Based on the requirements of improving the project management level, an evaluation index system with two levels of criterion level and index level is proposed, as shown in Table 2.

\section{Project full-cycle system evaluation model based on rough set-multi-level extension theory}

\subsection{Basic Introduction to Rough Set Theory}

Rough set theory, as a data analysis and processing theory, was founded in 1982 by Polish scientist Z. Pawlak. Rough set theory proposes a knowledge reduction method, which retains basic knowledge information, and at the same time guarantees that on the basis of the classification ability of the object, the repeated and redundant attributes and attribute values are eliminated, so as to realize the compression and rerefinement of the knowledge.

\subsection{Steps to Determine Weight based on Rough Set Theory}

Suppose an information system $S=(U, A, V, f)$ is given, where $U$ is the universe of discourse, that is, the set $U \neq \varnothing$ composed of all objects. A is a set of finite attributes or feature sets (including conditional attributes $\mathrm{C}$ and decision-making attributes $\mathrm{D}), A \neq \varnothing$. C is a set of conditional attributes, satisfying $A=C \cup D$ and $C \cup D \neq \varnothing . \mathrm{V}$ is the value range of the attribute. $\mathrm{f}$ is a mapping relationship, which can assign an information value to each attribute of each object. The importance of the condition attribute $\mathrm{c}$ in the condition attribute set $\mathrm{C}$ relative to the decision attribute $\mathrm{D}$ is calculated as follows:

$$
\operatorname{sig}(c, C, D)=r_{c}(D)-r_{c \nmid\{c\}}(D)=\frac{\left|\operatorname{POS}_{C}(D)\right|-\left|P O S_{c \dashv c\}}(D)\right|}{|U|}
$$

The weight of conditional attribute $c_{i}$ is:

$$
w_{i}=\frac{\operatorname{sig}(c, C ; D)}{\sum_{j=1}^{n} \operatorname{sig}\left(c_{j}, C ; D\right)}
$$

The establishment of a decision table starts with the basic indicators until the target decision table is established. Conditional attribute set $C=\left(c_{1}, c_{2}, \ldots, c_{i}\right)$ performs numerical processing on the information system and deletes duplicate content. I is a set of corresponding relations in $\mathrm{U}, X \in U$, then the set $\mathrm{X}$ is the lower approximation of I, which is the largest set of objects that must belong to $\mathrm{X}$ that are judged by existing knowledge, which is called the positive region of $\mathrm{X}$, Recorded as $\operatorname{POS}(X)$.

$$
I_{*}(X)=\{x \in U ; I(x) \in X\}
$$

Set $\mathrm{X}$ is the upper approximation of $\mathrm{I}$, is the union of all non-empty equivalent classes ${ }^{I}(X)$ that intersect with $\mathrm{X}$, and is the smallest set of objects that may belong to $\mathrm{X}$.

$$
I^{*}(X)=\{x \in U ; I(x) \cap X \neq \varnothing\}
$$

If the upper and lower are approximately equal, it is called an exact set, otherwise it is a rough set, where the lower approximation is called the positive region of the concept, and the difference between the upper and lower approximations is called the boundary. The area outside the upper approximation is called the negative area.

The dependence of decision attribute $\mathrm{D}$ on conditional attribute $\mathrm{C}$ is calculated as follows:

$$
r_{c}(D)=\frac{\left|\operatorname{POS}_{C}(D)\right|}{|U|}=\frac{\sum_{i=1}^{n}\left|\operatorname{POS}_{C}(y)_{i}\right|}{|U|}
$$

Remove each condition attribute $c_{i}$ in turn, and calculate the dependence of the decision attribute on the remaining condition attributes:

$$
r_{c-c_{i}}(D)=\frac{\left|\operatorname{POS}_{C-C_{i}}(D)\right|}{|U|}=\frac{\sum_{i=1}^{n}\left|\operatorname{POS}_{C-C_{i}}\left(y_{i}\right)\right|}{|U|}
$$

In this way, the importance of each condition attribute can be obtained:

$$
\sigma_{D}\left(C_{i}\right)=r_{c}(D)-r_{c-c_{i}}(D)
$$

Finally, use the formula to normalize to get the index weight.

\subsection{Basic Introduction of Multi-level Extension Evaluation Method}

Extenics theory is based on matter-element theory, extension set theory and correlation function theory. It studies its law of solving contradictory problems from both qualitative and quantitative perspectives.

\subsection{Evaluation Steps of Project Full Cycle System Based on Multi-level Extension Method}

Before carrying out the project full-cycle systematic evaluation, it is necessary to establish a multi-index and multi-level extension evaluation model, and then calculate the weight and correlation degree of each index 
in turn, so that the multi-index evaluation is transformed into a single-objective decision-making. The variables involved in this article are stipulated as follows: item level domain $U_{j}$, first-level evaluation index factor $\operatorname{set} C_{i}$, classic domain $R_{j}$, section domain $R_{u}$, object element $R_{i}$, item level $U_{j}$, specified value range $V_{j}$, the evaluation index factor set $C_{i}$ with respect to the range of values $V_{u}$ specified by all grades $\mathrm{U}, N_{i}$ is the object to be evaluated, and $V_{i k}$ is the value of $\mathrm{N}$ with respect to $C_{i k}$.

Classic domain:

$$
R_{j}=\left[U_{j}, C, V_{j}\right]=\left[\begin{array}{ccc}
U_{j} & C_{1} & \left\langle a_{j 1}, b_{j 1}\right\rangle \\
& C_{2} & \left\langle a_{j 2}, b_{j 2}\right\rangle \\
& \ldots & \ldots \\
& C_{n} & \left\langle a_{j n}, b_{j n}\right\rangle
\end{array}\right]
$$

Section domain:

$$
R_{u}=\left[U, C, V_{u}\right]=\left[\begin{array}{ccc}
U & C_{1} & \left\langle a_{i 1}, b_{u 1}\right\rangle \\
& C_{2} & \left\langle a_{u 2}, b_{u 2}\right\rangle \\
& \ldots & \ldots \\
& C_{n} & \left\langle a_{u n}, b_{u n}\right\rangle
\end{array}\right]
$$

Objects to be evaluated:

$$
R_{i}=\left[\begin{array}{ccc}
N & C_{i 1} & V_{i 1} \\
& C_{i 2} & V_{i 2} \\
\cdots & \cdots \\
& C_{i p} & V_{i p}
\end{array}\right]
$$

First establish the correlation function, and calculate the correlation degree of each evaluation index with respect to each level.

According to the definition of the correlation function, find the correlation degree of the secondary index of the object to be evaluated with respect to each level j. $k_{j}\left(c_{i j}\right)$ represents the correlation degree of the i-th first-level index and the k-th second-level index with respect to the level $\mathrm{j}$.

When $p\left(v_{i k}, \mathrm{v}_{u}\right)-p\left(v_{i k}, \mathrm{v}_{j}\right) \neq 0$, it is satisfied with the following formula:

$$
k_{j}=\frac{p\left(v_{i k}, \mathrm{v}_{j}\right)}{p\left(v_{i k}, \mathrm{v}_{u}\right)-p\left(v_{i k}, \mathrm{v}_{j}\right)}
$$

When $p\left(v_{i k}, \mathrm{v}_{u}\right)-p\left(v_{i k}, \mathrm{v}_{j}\right)=0$, it is satisfied with the following formula:

$$
\begin{gathered}
k_{j}\left(c_{i k}\right)=-p\left(v_{i k}, \mathrm{v}_{j}\right)-1 \\
p\left(v_{i k}, \mathrm{v}_{j}\right)=\left|v_{i k}-\frac{a_{j i}+b_{j i}}{2}\right|-\frac{b_{j i}-a_{j i}}{2} \\
p\left(v_{i k}, \mathrm{v}_{u}\right)=\left|v_{i k}-\frac{a_{u i}+b_{u i}}{2}\right|-\frac{b_{u i}-a_{u i}}{2}
\end{gathered}
$$

(2) Conduct secondary index evaluation

The correlation matrix $K\left(c_{i}\right)$ of each secondary indicator with respect to each risk level is obtained by multiplying the weight vector $w_{i k}$ of the secondary indicator with the correlation matrix $K\left(c_{i k}\right)=k_{j}\left(c_{i k}\right)$ of the secondary indicator with respect to each risk level. The formula is as follows:

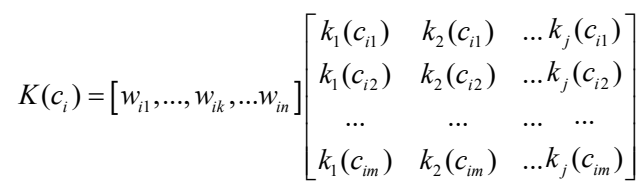

(3) Conduct first-level index evaluation

Multiply the weight vector $w_{j}$ of each first-level index with the correlation degree $K(c)=k\left(c_{i}\right)$ of the first-level index with respect to each risk level to obtain the correlation degree matrix $K(N)$ of the object to be evaluated with respect to each risk level.

(4) If $K_{j 0}=\max K_{j}(N)$, the object $\mathrm{N}$ to be evaluated belongs to level $\mathrm{j}$.

$$
\begin{gathered}
\bar{K}_{j}(N)=\frac{K_{j}(N)-\min _{j} K_{j}(N)}{\max _{j} K_{j}(N)-\min _{j} K_{j}(N)} \\
j^{*}=\frac{\sum_{j}^{m} j \times \bar{K}_{j}(N)}{\sum_{j=1}^{m} \bar{K}_{j}(N)}
\end{gathered}
$$

$j^{*}$ is the characteristic value of the level variable of the target layer, indicating the degree of belonging to a certain level.

\subsection{Multi-level extension evaluation method evaluation grade}

The multi-level extension evaluation method is used to divide the project full-cycle system evaluation grades into $\mathrm{j}(\mathrm{j}=1,2,3,4)$ grades, with 100 points as the scoring standard. The higher the score, the better the result of the project's full-cycle systematic evaluation. As shown in Table 1 .

Table 1. Project full-cycle system evaluation grade table based on multi-level extension evaluation method.

\begin{tabular}{|c|c|c|c|c|}
\hline $\begin{array}{c}\text { Evaluation } \\
\text { grade }\end{array}$ & $\mathbf{1}$ & $\mathbf{2}$ & $\mathbf{3}$ & $\mathbf{4}$ \\
\hline Description & $\begin{array}{c}\text { The } \\
\text { evaluation } \\
\text { results } \\
\text { good }\end{array}$ & $\begin{array}{c}\text { The } \\
\text { evaluation } \\
\text { results } \\
\text { better }\end{array}$ & $\begin{array}{c}\text { Results } \\
\text { were } \\
\text { generally }\end{array}$ & $\begin{array}{c}\text { Poor } \\
\text { evaluation } \\
\text { results }\end{array}$ \\
\hline $\begin{array}{c}\text { Scoring } \\
\text { standard }\end{array}$ & {$[90,100]$} & {$[75,90)$} & {$[60,75)$} & {$[0,60)$} \\
\hline
\end{tabular}




\section{Case analysis}

Determine the condition attribute $C=\left(c_{1}, c_{2}, c_{3}, c_{4}, c_{5}, c_{6}, c_{7}, c_{8}, c_{9}\right)$ of the project according to the criterion-level indicators in the project's full-cycle system evaluation system. Its decision-making attributes are divided into four levels, defined as $\mathrm{D}=$ (very good, good, fair, poor),

After digitizing the decision attributes, $D=(1,2,3,4)$ is obtained. The value of the decision attribute is based on the parameters of 10 completed projects randomly selected. The weight of each indicator is shown in Table 2

Table 2. The weight table of each evaluation index based on rough set theory.

\begin{tabular}{|c|c|c|c|}
\hline Criterion layer & Weights & Index layer & Weights \\
\hline \multirow{3}{*}{$\begin{array}{c}\text { Summary and } \\
\text { Evaluation of } \\
\text { Early-stage Project } \\
\text { Decisions }\end{array}$} & \multirow{3}{*}{0.1} & $\begin{array}{c}\text { Main opinions on project } \\
\text { evaluation and feasibility study } \\
\text { report approval }\end{array}$ & 0.5 \\
\hline & & $\begin{array}{c}\text { Project establishment conditions } \\
\text { and basis evaluation } \\
\end{array}$ & 0.375 \\
\hline & & $\begin{array}{c}\text { Decision-making process and } \\
\text { procedure evaluation }\end{array}$ & 0.125 \\
\hline \multirow{4}{*}{$\begin{array}{c}\text { Project } \\
\text { implementation } \\
\text { preparation and } \\
\text { evaluation }\end{array}$} & \multirow{4}{*}{0.1} & Survey and design evaluation & 0.5 \\
\hline & & Fund raising evaluation & 0.2 \\
\hline & & $\begin{array}{c}\text { Bidding and contract management } \\
\text { evaluation }\end{array}$ & 0.1 \\
\hline & & Evaluation of work preparation & 0.2 \\
\hline \multirow{5}{*}{$\begin{array}{l}\text { Summary and } \\
\text { Evaluation of } \\
\text { Project } \\
\text { Construction } \\
\text { Implementation }\end{array}$} & \multirow{5}{*}{0.15} & Progress control evaluation & 0.15 \\
\hline & & Quality control evaluation & 0.25 \\
\hline & & Safety control evaluation & 0.2 \\
\hline & & Investment control evaluation & 0.15 \\
\hline & & Completion acceptance evaluation & 0.25 \\
\hline \multirow{5}{*}{$\begin{array}{c}\text { Project } \\
\text { development } \\
\text { benefit evaluation }\end{array}$} & \multirow{5}{*}{0.2} & $\begin{array}{c}\text { Evaluation of the improvement of } \\
\text { power supply capacity index }\end{array}$ & 0.2 \\
\hline & & $\begin{array}{c}\text { Evaluation of the improvement of } \\
\text { grid structure index }\end{array}$ & 0.2 \\
\hline & & \begin{tabular}{|c|}
$\begin{array}{c}\text { Evaluation of the improvement of } \\
\text { utilization efficiency indicators }\end{array}$ \\
\end{tabular} & 0.2 \\
\hline & & \begin{tabular}{|c|}
$\begin{array}{c}\text { Evaluation of the improvement of } \\
\text { equipment level indicators }\end{array}$ \\
\end{tabular} & 0.2 \\
\hline & & \begin{tabular}{|c|} 
Evaluation of the improvement of \\
power supply quality indicators
\end{tabular} & 0.2 \\
\hline \multirow{2}{*}{$\begin{array}{c}\text { Project input and } \\
\text { output benefit } \\
\text { evaluation }\end{array}$} & \multirow[b]{2}{*}{0.15} & \begin{tabular}{|c|} 
Evaluation of the achievement of \\
project feasibility study goals
\end{tabular} & 0.6 \\
\hline & & $\begin{array}{l}\text { Evaluation of the operating } \\
\text { benefits of newly-added } \\
\text { equipment in the project }\end{array}$ & 0.4 \\
\hline \multirow{3}{*}{$\begin{array}{c}\text { Project } \\
\text { environmental } \\
\text { impact assessment }\end{array}$} & \multirow{3}{*}{0.1} & $\begin{array}{c}\text { Environmental impact compliance } \\
\text { status }\end{array}$ & 0.5 \\
\hline & & $\begin{array}{c}\text { Environmental protection facilities } \\
\text { construction and system } \\
\text { implementation } \\
\end{array}$ & 0.3 \\
\hline & & $\begin{array}{l}\text { Environmental impact and } \\
\text { ecological protection effect }\end{array}$ & 0.2 \\
\hline \begin{tabular}{|c|} 
Project social \\
benefit evaluation
\end{tabular} & 0.05 & $\begin{array}{l}\text { Impact on regional employment } \\
\text { and the improvement of people's }\end{array}$ & 0.375 \\
\hline
\end{tabular}

\begin{tabular}{|c|c|c|c|}
\hline Criterion layer & \begin{tabular}{|l|} 
Weights \\
\end{tabular} & Index layer & Weights \\
\hline & & living standards & \\
\hline & & \begin{tabular}{|c|} 
Impact on regional economic and \\
social development \\
\end{tabular} & 0.375 \\
\hline & & $\begin{array}{c}\text { Impact on the advancement of } \\
\text { industrial technology }\end{array}$ & 0.25 \\
\hline \multirow{3}{*}{$\begin{array}{c}\text { Project } \\
\text { sustainability } \\
\text { evaluation }\end{array}$} & \multirow{3}{*}{0.1} & $\begin{array}{c}\text { Evaluation of the impact of the } \\
\text { external environment }\end{array}$ & 0.25 \\
\hline & & $\begin{array}{c}\text { Impact assessment of internal } \\
\text { environment }\end{array}$ & 0.25 \\
\hline & & Repeatability evaluation & 0.5 \\
\hline \multirow{3}{*}{$\begin{array}{c}\text { Project success } \\
\text { evaluation }\end{array}$} & \multirow{3}{*}{0.05} & $\begin{array}{l}\text { Cultivation and promotion of } \\
\text { enterprise's technical strength }\end{array}$ & 0.2 \\
\hline & & $\begin{array}{c}\text { Contribution of the project to the } \\
\text { economic benefits of the } \\
\text { enterprise }\end{array}$ & 0.35 \\
\hline & & $\begin{array}{c}\text { The impact of project construction } \\
\text { and operation on the management } \\
\text { level of the enterprise }\end{array}$ & 0.45 \\
\hline
\end{tabular}

Taking a power grid infrastructure project as an example, a project full-cycle system evaluation model based on multi-level extension evaluation method.

Table 3 shows the correlation degree of the criterion level about the project full-cycle system evaluation grade.

Table 3. Correlation degree of criterion-level indicators with regard to the evaluation level of the project's full-cycle system.

\begin{tabular}{|c|c|c|c|c|c|c|c|c|}
\hline \multirow{2}{*}{$\begin{array}{c}\text { Criterion-level } \\
\text { indicators }\end{array}$} & $j=1$ & $j=2$ & $j=3$ & $j=4$ & $\max$ & $\min$ & $j^{*}$ & $\begin{array}{c}\text { Correlation } \\
\text { on } \\
\text { grade }\end{array}$ \\
\cline { 2 - 7 } $\begin{array}{c}\text { Summary and } \\
\text { Evaluation of Early- } \\
\text { stage Project Decisions }\end{array}$ & 0.18 & -0.11 & -0.65 & -0.78 & 0.18 & -0.78 & 1.53 & 2 \\
\hline $\begin{array}{c}\text { Project implementation } \\
\text { preparation and } \\
\text { evaluation }\end{array}$ & 0.31 & -0.03 & -0.61 & -0.76 & 0.31 & -0.76 & 1.17 & 1 \\
\hline $\begin{array}{c}\text { Summary and } \\
\text { Evaluation of Project } \\
\text { Construction } \\
\text { Implementation }\end{array}$ & 0.86 & -0.07 & -0.63 & -0.77 & 0.86 & -0.77 & 2.15 & 2 \\
\hline $\begin{array}{c}\text { Project development } \\
\text { benefit evaluation }\end{array}$ & 0.71 & -0.24 & -0.70 & -0.81 & 0.71 & -0.81 & 1.48 & 2 \\
\hline $\begin{array}{c}\text { Project input and output } \\
\text { benefit evaluation }\end{array}$ & -0.25 & 0.06 & -0.23 & -0.52 & 0.06 & -0.70 & 1.77 & 2 \\
\hline $\begin{array}{c}\text { Project environmental } \\
\text { impact assessment }\end{array}$ & 0.22 & -0.07 & -0.58 & -0.74 & 0.22 & -0.74 & 1.55 & 2 \\
\hline $\begin{array}{c}\text { Project social benefit } \\
\text { evaluation }\end{array}$ & 0.13 & -0.07 & -0.42 & -0.63 & 0.13 & -0.63 & 0.72 & 1 \\
\hline $\begin{array}{c}\text { Project sustainability } \\
\text { evaluation }\end{array}$ & -0.13 & 0.25 & -0.50 & -0.69 & 0.25 & -0.69 & 1.99 & 2 \\
\hline $\begin{array}{c}\text { Project success } \\
\text { evaluation }\end{array}$ & -0.32 & 0.37 & -0.24 & -0.53 & 0.50 & -0.53 & 1.74 & 2 \\
\hline
\end{tabular}

In the evaluation results, the preparation and evaluation of the project implementation and the evaluation results of the social benefits of the project are very good. Early-stage project decision-making summary and evaluation, project construction 
implementation summary and evaluation, project development benefit evaluation, project input and output benefit evaluation, project environmental impact evaluation, project sustainability evaluation, project success evaluation results are good, and there is room for improvement.

Combining the extension evaluation results of the criterion-level indicators in Table 3 , and combining formulas (15)-(17), the feature value of the system evaluation grade variable of the project can be calculated to be 1.56. Which indicates that the degree of its completion is between level 1 and 2, indicating that the project's full-cycle systematic evaluation results are better.

The results of calculation examples show that the project life cycle system evaluation model based on rough set theory and multi-level extension evaluation can achieve the purpose of project post-evaluation. The indicator system covers all aspects of power grid projects, and the evaluation methods used are highly operability, weaken the subjective color of evaluation, and improve the accuracy of post-project evaluation.

\section{Conclusion}

This article is divided into 9 aspects to establish a project full-cycle systematic evaluation system, which fully reflects the evaluation of various benefits of each link of the project. According to the attributes and characteristics of the indicators, the rough set theory is selected to determine the weights of the indicators, and the multi-level extension evaluation method is selected for the full-cycle system evaluation of the project, which provides a post-evaluation method with practical value for power grid enterprises, and has a certain reference effect.

\section{Acknowledgment}

This work was supported by the 2020 Science and Technology Project of the State Grid Corporation of China. Project name: Research on Intelligent Management and Control Technology and Application of Data-Driven Power Grid Enterprise Project, Project no. JSB17202000260.

\section{References}

1. L. Bin, "Talking about the impact of power system reform on power grid enterprises," China Electric. Beijing, 11, (2014)

2. H. Yuan, L. Wei, and Z. Chenxu, "Research on Current Situation and Countermeasures of Distribution Network Management," Rural Power Management. Beijing,11, (2018)

3. D W. Van, M D. Pandey, "A stochastic process model for life cycle cost analysis of nuclear power plant systems," CRC Press/Balkema - Taylor \& Francis Group. 34, (2013)
4. K.Wang, F. Sun, and Z. Lan, "Application of Life Cycle Cost Management in Network Planning of Actual Power System," Electric Power Construction, (2016)

5. Y.Katagiri, N. Nagafuchi, and T. Yoshida, "Power plant life cycle costing system and power plant life cycle costing method," US, EP2290596, (2011)

6. L.Yufang, T. Jian, and X.Chao, "Research on Investment Decision Management and Control of Power Grid Projects from the Perspective of Whole Life Cycle," Urban Construction Theory Research. Beijing, 13, (2020)

7. T.Kuo, W.Wei, “Accurate Grid Investment Strategy under the Condition of Transmission and Distribution Price Reform," Smart power. Shaanxi, 46, (2018)

8. S.Donglin, F. Binghai, T.Heng, "Construction of Process Management Evaluation System for Science and Technology Planning Projects Based on the Whole Life Cycle," Scientific Management Research. Inner Mongolia, 29, (2011) 